
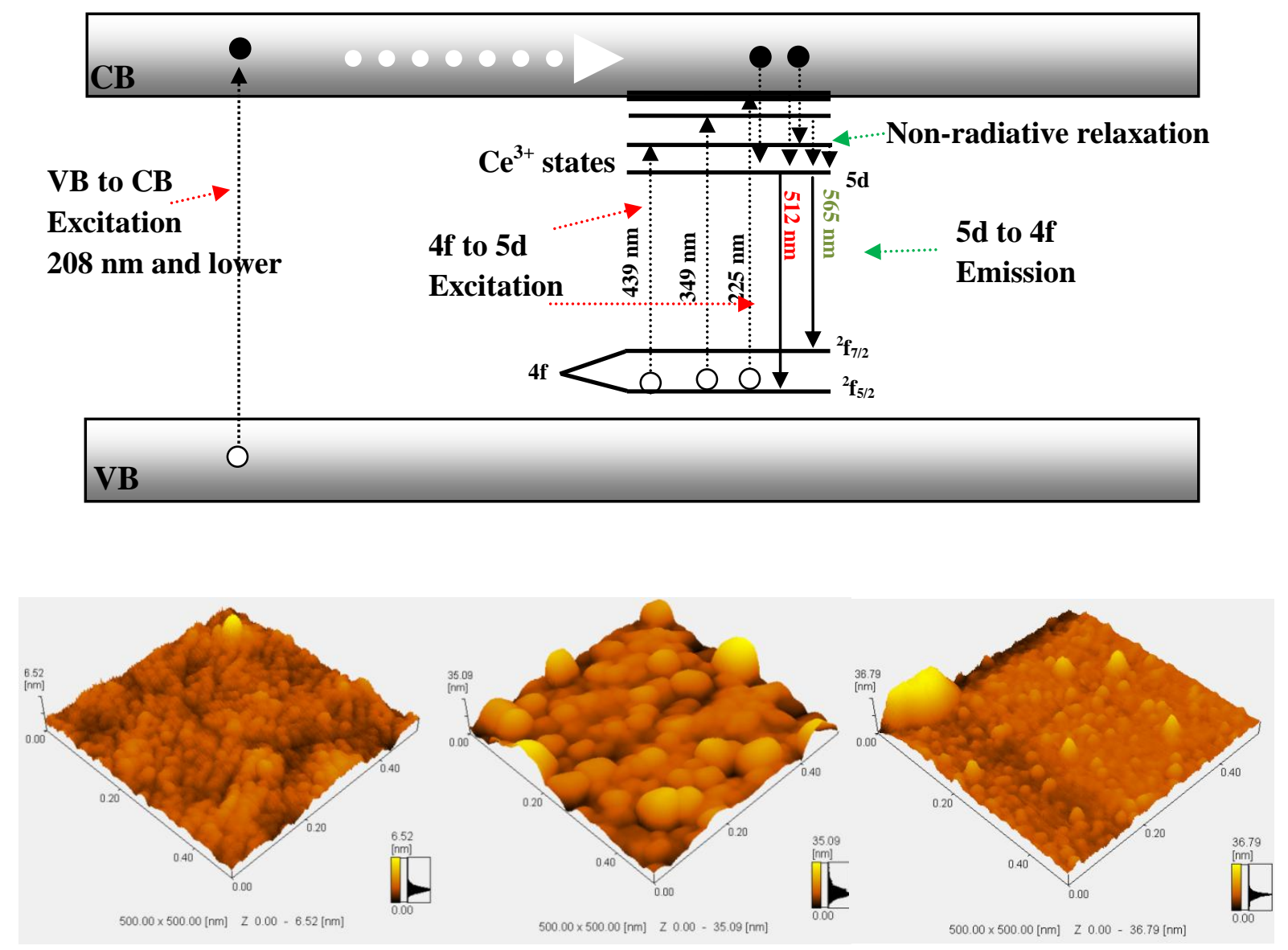

The energy diagram of the $\mathrm{Y}_{3}(\mathrm{AlGa})_{5} \mathrm{O}_{12}: \mathrm{Ce}^{3+}$ phosphor was constructed from excitation and emission data and thin films were grown with pulsed laser deposition in different background atmospheres. 


\title{
The effect of different gas atmospheres on the structure, morphology and photoluminescence properties of pulsed laser deposited $\mathrm{Y}_{3}(\mathrm{Al}, \mathrm{Ga})_{5} \mathrm{O}_{12}: \mathrm{Ce}^{3+}$ nano thin films.
}

\author{
S.T.S. Dlamini, H.C. Swart*, J.J. Terblans and O.M. Ntwaeaborwa \\ Department of Physics, University of the Free State, P O Box 339, Bloemfontein, ZA-9300, South \\ Africa \\ *E-mail: SwartHC@ufs.ac.za; Tel: +27514012926
}

\begin{abstract}
Luminescent properties of $\mathrm{Y}_{3}(\mathrm{Al}, \mathrm{Ga})_{5} \mathrm{O}_{12}: \mathrm{Ce}^{3+}$ phosphor powder and thin films were obtained. The phosphor powder was used as target material for Pulsed Laser Deposition (PLD) of the thin films in the presence of different background gases. Excitation peaks for the powder were obtained at 439, 349, 225 and $189 \mathrm{~nm}$ and emission peaks at 512 and $565 \mathrm{~nm}$. X-ray diffraction indicated that better crystallization took place for films deposited in a 20 mtorr $\mathrm{O}_{2}$ atmosphere. Atomic force microscope revealed an RMS value of $0.7 \mathrm{~nm}, 2.5 \mathrm{~nm}$ and $4.8 \mathrm{~nm}$ for the films deposited in vacuum, $\mathrm{O}_{2}$ and $\mathrm{Ar}$ atmospheres, respectively. The highest $\mathrm{PL}$ intensity was observed for films deposited in the $\mathrm{O}_{2}$ atmosphere. A slight shift in the wavelength of the PL spectra was obtained for the thin films due to a change in the crystal field. The thickness of the films varied from $120 \mathrm{~nm}$ to $270 \mathrm{~nm}$ with films deposited in vacuum having the thin layer and those in Ar having the thick layer. The stoichiometry of the powder was maintained in the film during the deposition as confirmed by Rutherford Backscattering Spectroscopy.
\end{abstract}

Keywords: $\mathrm{Y}_{3}(\mathrm{Al}, \mathrm{Ga})_{5} \mathrm{O}_{12}: \mathrm{Ce}^{3+}$; Pulsed Laser Deposition; different gas atmospheres. 


\section{Introduction}

Cerium-doped yttrium aluminum gallium garnet $\left(\mathrm{Y}_{3}(\mathrm{Al}, \mathrm{Ga})_{5} \mathrm{O}_{12}: \mathrm{Ce}^{3+} / \mathrm{YAGG}: \mathrm{Ce}\right)$ powder phosphor is a modified form of the more traditional yttrium aluminum garnet $\left(\mathrm{Y}_{3} \mathrm{Al}_{5} \mathrm{O}_{12}: \mathrm{Ce}^{3+} / \mathrm{YAG}: \mathrm{Ce}\right)$ phosphor. In YAG, 3.75 atoms of Ga are substituted with 1.25 atoms of $\mathrm{Al}$ on average for YAGG:Ce. Fasoli et al. [1] employed a combination of first-principle calculations and optical characterization experiments to explain the mechanism by which $\mathrm{Ga}^{3+}$ doping prevents the trapping of free carriers due to shallow traps. They confirm that $\mathrm{Ga}^{3+}$ doping does not reduce the defect concentration, but rather leads to shifts in the valence and conduction bands such that the energy level of shallow defects is no longer in the forbidden gap where electrons can be trapped. YAG:Ce is used in several applications such as solid-state lighting, displays, scintillators, and thermographic phosphors (TGP ) [1]. YAG is transparent and colorless in the visible range. YAG's optical band gap is in the order of $6.6 \mathrm{eV}$, with the valence band comprised of filled oxygen $2 \mathrm{p}$ orbitals, and the conduction band comprised of empty yttrium 4d orbitals. The UV absorption between $300 \mathrm{~nm}$ and the band edge at $190 \mathrm{~nm}$ varies dramatically from crystal to crystal [3]. YAG: $\mathrm{Ce}^{3+}$ mainly belongs to the luminescent materials with individual luminescent centers. The $\mathrm{Ce}^{3+}$ ion has only one electron in the $4 \mathrm{f}$ state. The ground state is split into a ${ }^{2} \mathrm{f}_{5 / 2}$ and a ${ }^{2} \mathrm{f}_{7 / 2}$ level by the spin-orbit interactions. The first excited state originates from the $5 \mathrm{~d}$ state, which interacts strongly with the host lattice due to the large spatial extent of the $5 \mathrm{~d}$ wave function. Thus the crystal-field interaction dominates over the spinorbit interaction and the $4 \mathrm{f}$ to $5 \mathrm{~d}$ transitions are parity and spin allowed [4]. When a $\mathrm{Ce}^{3+}$ ion enters exclusively one specific lattice site, its $5 \mathrm{~d}$ state will be split into $2-5$ different components depending on the site symmetry [5]. The 5d state may also split into several more components if present in more than one lattice position with different site symmetry. $\mathrm{Ce}^{3+}$ doped phosphors 
typically have two emission bands due to the true levels of ${ }^{2} f_{5 / 2}$ and ${ }^{2} f_{7 / 2}$ of the $4 f$ configuration of $\mathrm{Ce}^{3+}[6,7]$. Coetsee et. al. [8] found that the cathodoluminescent (CL) and PL emission spectra for $\mathrm{Y}_{2} \mathrm{SiO}_{5}: \mathrm{Ce}^{3+}$ phosphor powder due to the $\mathrm{Ce}^{3+}$ ions were attributed to the two different sites (A1 and A2) of the $\mathrm{Ce}^{3+}$ ion in the host matrix and the difference in the orientation of the neighbor ions in the complex crystal structure. Each $\mathrm{Ce}^{3+}$ site gave rise to transitions from the $5 \mathrm{~d}$ to the two (therefore two peaks) $4 \mathrm{f}$ energy levels $\left({ }^{2} \mathrm{f}_{5 / 2}\right.$ and ${ }^{2} \mathrm{f}_{7 / 2}$ due to crystal field splitting). For the understanding of the lanthanide fd structure, knowledge about the excitation spectrum of the $\mathrm{Ce}^{3+}$ ion in a certain host lattice is very important. The $\mathrm{Ce}^{3+}$ ion has the $4 \mathrm{f}^{1}$ configuration, and irradiation with UV radiation will excite this $4 \mathrm{f}$ electron into a $5 \mathrm{~d}$ orbital, leaving the $4 \mathrm{f}$ shell empty. Therefore, the excitation spectrum of $\mathrm{Ce}^{3+}$ will give direct information on the crystalfield splitting of the $5 d$ orbitals. A similar crystal-field splitting is expected for all rare-earth ions in the same host lattice. The crystal-field splitting of the $5 \mathrm{~d}$ states dominates the structure in the fd excitation spectra, even in the more complex rare-earth ions with more than one $4 \mathrm{f}$ electron cases [9]. Recently attention has been paid on YAG:Ce because it can be applied to white light emitting diodes (LEDs) as yellow emission phosphors. The $\mathrm{Ce}^{3+}$ ion is responsible for nanosecond decay times and an intense yellow-green emission wavelength [10]. Trivalent Ga atoms have been substituted for $\mathrm{Al}$ atoms in order to blue-shift the emission wavelength for use in solid-state light applications such as fabrication of white LEDs. The most common method to produce white light with LEDs is the combination of blue InGaN-GaN LEDs with the yellow emitting YAG:Ce phosphor. With a LED emission wavelength of $440-470 \mathrm{~nm}$ a fraction of the LED emission is absorbed by the YAG:Ce phosphor and down-converted to the well-known broad yellow emission of the phosphor. Not converted blue LED light and the yellow emission 
are mixed by the phosphor powder layer to obtain white light in a wide range of correlated color temperatures (CCT) from 4000 - $8000 \mathrm{~K}$ [11].

It has been shown that YAGG:Ce has characteristics that are suitable for this phosphor to be applied for the fabrication of LEDs [12]. However in literature YAGG:Ce has been studied rather extensively in the powder form but not so much in the thin film form. Particularly thin films that have been prepared by the pulsed laser deposition (PLD) technique did not gain much attention in the past. $\mathrm{Y}_{3-\mathrm{x}} \mathrm{Al}_{5} \mathrm{O}_{12}: \mathrm{Ce}_{\mathrm{x}}{ }^{3+}\left(\mathrm{YAG}: \mathrm{Ce}^{3+}\right)$ thin-films were deposited by a pulsed-laser deposition method on quartz substrates using a solid YAG:Ce target [13]. The as-deposited films were amorphous and annealing above $900{ }^{\circ} \mathrm{C}$ was required to obtain crystallization. PL spectra of annealed films showed a strong and broad emission band around $570 \mathrm{~nm}$ and excitations at 342 and $460 \mathrm{~nm}$, all corresponding to transitions between the $4 \mathrm{f}^{1}$ ground level to the $5 \mathrm{~d}^{1}$ excited levels of $\mathrm{Ce}^{3+}$ ion. Thin films offers several advantages due to their good luminescence characteristics, higher image resolution from small grains, better thermal stability and good adhesion to the substrate [12]. The presence of a background gas in a chamber plays an important role in the growth of the thin films during the PLD. There are 3 primary processes which take place on a microscopic scale: the atom/ion reflection on the surface, sputtering of film atoms by the deposited atoms and implantation of arriving atoms [14]. Depending on the pressures inside the chamber, whether the chamber is in vacuum or in the presence of a background gas, one or two of these microscopic processes will be more favored and this significantly affects the growth and properties of the film. In this paper we report on the morphological and luminescent properties of YAGG:Ce phosphor in the powder form and the thin film prepared by PLD with in vacuum and in a background gas of Ar and background gas of $\mathrm{O}_{2}$ at pressures of 5 mtorr, 10 mtorr and 20 mtorr for both gases. The aim was to identify the 
PLD gas environment that will produced thin films with a high PL intensity as well as structural properties similar to the YAGG:Ce phosphor in the powder form.

\section{Experimental Setup}

$\mathrm{Y}_{3}(\mathrm{Al}, \mathrm{Ga})_{5} \mathrm{O}_{12}: \mathrm{Ce}^{3+}$ powder phosphor obtained from Phosphor Technology (UK) with Commission Internationale de l'Eclairage (CIE) chromaticity coordinates: $(x=0.306, y=0.521)$ and non-uniform particles with median particle size of $2.5 \mu \mathrm{m}$ were used in this study [15]. The Ga to $\mathrm{Al}$ ratio is about 60:40 in the $\mathrm{Y}_{3}(\mathrm{AlGa})_{5} \mathrm{O}_{12}: \mathrm{Ce}^{3+}$ crystal structure. When $\mathrm{Al}^{3+}$ is substituted with $\mathrm{Ga}^{3+}$, the Ga-O bonds re-adjust due to the difference in atomic radius of $\mathrm{Ga}^{3+}$ which is larger than $\mathrm{Al}^{3+}$. The powder was first completely characterize and then pressed without binders to make a pellet which was used as a target for PLD. Silicon (100) wafers were used as substrates. They were cut into approximately $2 \mathrm{~cm}$ by $2 \mathrm{~cm}$ pieces and cleaned in an acetone ultrasonic bath for 15 minutes. A layer of silicon dioxide was grown on all the films. The phosphor target and one silicon piece at a time were inserted into the PLD chamber. An Nd:YAG $266 \mathrm{~nm}$ laser was used to deposit the phosphor target. The laser fluency was kept at $0.78 \mathrm{~J} / \mathrm{cm}^{2}$ with a $10 \mathrm{~Hz}$ frequency. The target to substrate distance was kept at $6 \mathrm{~cm}$. The chamber was evacuated to a base pressure of $5 \times 10^{-6}$ mbar. A film was deposited with a substrate temperature at $300^{\circ} \mathrm{C}$ at a vacuum pressure of $8 \times 10^{-6}$ mbar. Then the chamber was backfilled with $\mathrm{Ar}$ and then $\mathrm{O}_{2}$ gas. The ablation was performed at a chamber's pressure of 5 mtorr, 10 mtorr and 20 mtorr for both background gases while the substrate temperature was kept constant at $300^{\circ} \mathrm{C}$. Atomic Force Microscopy (AFM) was used to obtain micrographs of the surface using the Shimadzu SPM 9600 model. The root mean square (RMS) values were obtained with the commercial software coming with the AFM system. Photoluminescence (PL) excitation and emission spectra ware recorded using a Cary Eclipse fluorescence spectrophotometer (Model: LS 55) at room 
temperature using a $140 \mathrm{~W}$ monochromatized Xenon flash lamp as an excitation source. The slit (aperture) used between the lamp and the sample was adjust in such a way that a large part of the sample was exposed to the excitation beam to make sure an average emission intensity was obtained over a large area of the thin film and possible un-uniformities in the thin films if any are cancelled out if an average emission intensity is obtained. The UV-VUV excitation spectra of the $\mathrm{Y}_{3}(\mathrm{AlGa})_{5} \mathrm{O}_{12}$ : $\mathrm{Ce}^{3+}$ powder were also recorded by using the UV-VUV synchrotron radiation facility at the SUPERLUMI beamline I of HASYLAB (Hamburger Synchrotron strahlungslabor) at DESY (Deutsches Elektronen-Synchrotron, Hamburg, Germany) [16]. The spectra were recorded at room temperature. The setup consisted of a 2-m McPherson type primary (excitation) monochromator with a resolution up to $0.02 \mathrm{~nm}$. The UV-VUV excitation spectra were corrected for the variation in the incident flux of the excitation beam using the excitation spectrum of sodium salicylate as a standard. X-Ray Diffraction (XRD) data was collected by using a D5000 diffractometer using $\mathrm{CuK} \alpha$ radiation of $\lambda=1.5405 \mathrm{~nm}$ in the $2 \theta$ range from $10^{\circ}-66^{\circ}$, with a counting time of $2 \mathrm{~s}$ for each step size of $0.0302^{\circ}$. Rutherford backscattering spectroscopy (RBS) was used to collect composition and thickness information of the thin films. The films were irradiated with $2 \mathrm{Me} \mathrm{He}^{+}$ions. Auger Electron Spectroscopy (AES)'s depth profiles and AES survey test of the surface before and after depth profile where performed using a PHI 700 Scanning Auger Nanoprobe. AES surveys were done with a 25 kV 10 nA electron beam. Depth profiles were sputtered with a $2 \mathrm{kV}, 2 \mu \mathrm{A}$ ion beam, at $1 \times 1 \mathrm{~mm}$ raster area with sputter rate of 27 nm per min.

\section{Results and discussion}

In the relative arrangement of $\mathrm{Y}, \mathrm{O}, \mathrm{Al}$ and $\mathrm{Ga}$ in $\mathrm{Y}_{3}(\mathrm{Al}, \mathrm{Ga})_{5} \mathrm{O}_{12}: \mathrm{Ce}^{3+}$ the $\mathrm{Y} / \mathrm{Ce}$ ions are surrounded by $\mathrm{O}^{2-}$ ions in the dodecahedral arrangement. The $\mathrm{Al}^{3+}$ and $\mathrm{Ga}^{3+}$ are surrounded by 
$\mathrm{O}^{2-}$ ions in a tetrahedral and octahedral arrangement. Ultimately, the substitution of Ga into the YAG lattice results in a decompression of oxygen atoms directly coordinated to the $\mathrm{Ce}^{3+}$ atom which leads the structure to become more cubic. This change in structure directly affects the $5 \mathrm{~d}$ orbitals of the $\mathrm{Ce}^{3+}$ and likewise the PL characteristics [17].

The excitation and emission spectra of the $\mathrm{Y}_{3}(\mathrm{AlGa})_{5} \mathrm{O}_{12}: \mathrm{Ce}^{3+}$ phosphor powder measured with the Cary Eclipse fluorescence spectrophotometer are shown in figure 1. Excitation peaks were obtained at $349 \mathrm{~nm}$ and $439 \mathrm{~nm}$ with a shoulder at $225 \mathrm{~nm}$. An emission peak at $512 \mathrm{~nm}$ with a shoulder peak at $565 \mathrm{~nm}$ is clear from the emission spectrum. The emission and excitation spectra of $\mathrm{Y}_{3}(\mathrm{AlGa})_{5} \mathrm{O}_{12}: \mathrm{Ce}^{3+}$ were also obtained under UV-VUV synchrotron radiation, figure 2. The excitation spectra of the host were measured at $178 \mathrm{~nm}$ and $225 \mathrm{~nm}$ at room temperature. Except for the intensity difference the spectra are identical with a broad peak consisting out of two peaks at around 512 and $565 \mathrm{~nm}$. These peaks are from the de-excitation of electrons from the lowest $5 \mathrm{~d}$ level to the field splitted $4 \mathrm{f}\left({ }^{2} \mathrm{f}_{5 / 2}\right.$ and a $\left.{ }^{2} \mathrm{f}_{7 / 2}\right)$ levels. The excitation spectrum shown in figure 2 was measured from the $512 \mathrm{~nm}$ emission. Excitation peaks were obtained at 349, 439, 225 and $189 \mathrm{~nm}$, figure 1 and 2. The last peak that increases from $209 \mathrm{~nm}$ up to $189 \mathrm{~nm}$ is assigned to the host-related absorption, since many phosphors show host-related absorptions around this spectral range [5]. In this case it is an indication of the band gap absorption of the $\mathrm{Y}_{3}(\mathrm{AlGa})_{5} \mathrm{O}_{12}$ between $5.96 \mathrm{eV}(208 \mathrm{~nm})$ and $6.56 \mathrm{eV}(189 \mathrm{~nm})$. The other excitation peaks clearly indicate the excitation peaks of the $4 \mathrm{f}\left({ }^{2} f_{7 / 2}\right)$ to $5 d$ levels. It is therefore clear that the $\mathrm{Ce}^{3+}$ is excited via the conduction band as well as in the $\mathrm{Ce}^{3+}$ ion itself. The PL emission spectrum obtained by Chaoa et al. [18] had a broad emission band that was centered at $545 \mathrm{~nm}$. This emission corresponds to the transition from the $5 \mathrm{~d}$ excited state to the $4 \mathrm{f}$ ground state of the $\mathrm{Ce}^{3+}$ ion in the YAG crystal. Their PL excitation spectrum includes two peaks at $340 \mathrm{~nm}$ (weak) and 
$450 \mathrm{~nm}$ (strong), which correspond to the characteristic 5d and 4f energy levels. A summary of the energy levels of $\mathrm{Ce}^{3+}$ in the $\mathrm{Y}_{3}(\mathrm{AlGa})_{5} \mathrm{O}_{12}$ is given in figure 3 as obtained and compiled from the measured excitation and emission spectra. The $225 \mathrm{~nm}$ excitation and the $209 \mathrm{~nm}$ is very close to each other indicating that one of the $5 \mathrm{~d}$ level must be on the edge of the $\mathrm{CB}$. The $\mathrm{Ce}^{3+}$ energy values of the $5 d$ lines obtained from this study compared very well with that obtained by Tomiki et. al. [19]. The values from Tomiki are: $460 \mathrm{~nm}(2.695 \mathrm{eV}) ; 340 \mathrm{~nm}(3.643 \mathrm{eV}) ; 266 \mathrm{~nm}$ (4.66 eV); $228 \mathrm{~nm}(5.44 \mathrm{eV})$ and $204 \mathrm{~nm}(6.07 \mathrm{eV})$. In the YAGG:Ce system [17], replacement of $\mathrm{Al}$ with the larger $\mathrm{Ga}$ ion in the octahedral site increases the lattice constant and decreases the peak excitation/emission wavelength. Excitation and emission values shows that decreasing the lattice constant actually increases the peak emission wavelength while barely affecting the excitation maxima. Kottaisamy et al. [19] found a peak shift to the higher wavelength region which indicated that the lowest $5 \mathrm{~d}$ level has shifted to a much lower energy level due to codoping with higher ionic size ions (Gd or La) at the Y site of YAG. XRD patterns of the YAGG:Ce phosphor powder and thin films that were deposited in various atmospheres before and after annealing are shown in figure 4 and figure 5 respectively. The ICSD file number 29250 is also shown. Note that the (420) peaks are cut off in order to enlarge the other reflections. It is clear that crystalline thin films with the same crystal structure then the powder were obtained during the PLD process. The films annealed at $800{ }^{\circ} \mathrm{C}$ have only a small effect (improvement) on the crystallinity of the thin film. The XRD peaks of the $\mathrm{O}_{2}$ are more pronounced which indicate that better crystallinity was obtained in the $\mathrm{O}_{2}$ atmosphere. The XRD of the other annealed films prepared at the other pressures was similar to the spectra shown.

The micrographs obtained, figure 6 and 7 , showed films grown on the silicon substrate under different background atmospheres as indicated. From this AFM images, figure 6, it can be seen 
that films deposited in (a) vacuum (1.6 $\times 10^{-6}$ mbar) are smooth and consist of small nanoparticles, while the films deposited in (b) 20 mtorr Ar atmosphere, have rough surfaces that consist of much bigger particles. The surfaces of the thin film deposited in (c) 20 mtorr $\mathrm{O}_{2}$ were also much smoother but much more defined and also consist of nanoparticles. During deposition in vacuum, the plume leaves the target with very high energy and travels through the chamber to the substrate. In the absence of a background gas, the particles making up the plume (atoms, ions and electrons) are likely to be reflected when they reach the substrate or sputter the already growing film. The SEM image in figure 7(a) shows areas on the surface where the material was sputtered or no deposition took place (indicated by the black arrows). Figure 7(b) shows a SEM image of a film deposited in an Ar and (c) $\mathrm{O}_{2}$ atmosphere of 20 mtorr. During a PLD experiment with the pulse of a nanosecond duration the laser energy is initially absorbed by the electrons in the solid target material, the strong energy deposition leads to an explosive evaporation of ions, electrons and neutral atoms called the plume. The initial high pressure drives the ablation plume towards the background gas. The plume slows down and is confined in the background gas. Eventually, the atoms diffuse out of the plume and migrate to the substrate or the chamber walls [22-25]. The angular distribution of the plume atoms is influenced by the mass density of the background gas. For heavy gases the broadening of the angular distribution is bigger than the broadening in light gases. This simply means light atoms in a heavy gas are scattered much more than heavy atom in a heavy gas [26-27]. Background gas of Ar has a mass density higher than that of $\mathrm{O}_{2}$ and therefore thus tends to reflect lighter atoms in the plume more and these results in a film with big particles on the substrate as seen in figure 6 (b) and figure 7 (b). $\mathrm{O}_{2}$ background has a lighter mass density relative to Ar and thus results in small broadening of the angular 
distribution which results in a thin film with small and evenly distributed particles as seen in figure 6(c).

From the AFM's RMS value which is an indication of the roughness of the surface of the thin films it could be seen that films deposited in 20 mtorr Ar are more rough followed by those deposited in 20 mtorr $\mathrm{O}_{2}$ as a background gas while films deposited in vacuum $\left(1.6 \times 10^{-6} \mathrm{mbar}\right)$ are the smoothest with an RMS value of $0.7 \mathrm{~nm}, 2.5 \mathrm{~nm}$ and $4.8 \mathrm{~nm}$ for the films deposited in vacuum, $\mathrm{O}_{2}$ and $\mathrm{Ar}$ and atmospheres, respectively.

Figure 8 shows the PL intensity of the films deposited in $\mathrm{O}_{2}$ at various background gas pressures in the chamber. The emission spectra of the films were obtained under excitation of the host at $345 \mathrm{~nm}$ and $435 \mathrm{~nm}$ at room temperature. Except for the intensity difference the spectra are more or less identical with a broad peak consisting of two peaks at around $502 \mathrm{~nm}$ and $545 \mathrm{~nm}$. These peaks are from the de-excitation of electrons from the lowest $5 \mathrm{~d}$ level to the field split $4 \mathrm{f}\left({ }^{2} \mathrm{f}_{5 / 2}\right.$ and $a^{2} f_{7 / 2}$ ) levels as is the case with the powder. The shape of the emission spectra of the films are identical to those of $\mathrm{Y}_{3}(\mathrm{Al}, \mathrm{Ga})_{5} \mathrm{O}_{12}: \mathrm{Ce}^{3+}$ in the powder form except there is a definite shift in the peak positions towards lower wavelengths. This shift can be attributed to the crystal field effect on the $5 d$ level of the $\mathrm{Ce}^{3+}$ ion. The PL intensity increases with an increasing pressure for both sets of films deposited in $\mathrm{Ar}$ and in $\mathrm{O}_{2}$ as shown as inset in figure 8. But a more intense increase is observed for films deposited in an $\mathrm{O}_{2}$ background. PL spectra obtained by Choe [13] from annealed PLD YAG:Ce ${ }^{3+}$ films showed a strong and broad emission band around $570 \mathrm{~nm}$ and excitations at 342 and $460 \mathrm{~nm}$, clearly pointed out the influence on the wavelength positions due to the Ga in our films. Figure 9 shows the relative placement of the $5 \mathrm{~d}$ orbitals in $\mathrm{Y}_{3} \mathrm{Al}_{5} \mathrm{O}_{12}: \mathrm{Ce}^{3+}$ (YAG: $\left.\mathrm{Ce}\right)$ and $\mathrm{Y}_{3}(\mathrm{Al}, \mathrm{Ga})_{5} \mathrm{O}_{12}: \mathrm{Ce}^{3+}$ (YAGG:Ce) [26]. Electrons are excited to the $\mathrm{E}^{\prime \prime}$ state of the $5 \mathrm{~d}$ orbital and are emitted from the $\mathrm{E}^{\prime}$ state. The splitting of the $\mathrm{E}^{\prime \prime}$ and $\mathrm{E}^{\prime}$ states 
is determined by the crystal field around the $\mathrm{Ce}^{3+}$ ion. In films that have less Ga on the surface, the oxygen atoms around the $\mathrm{Ce}^{3+}$ ion are highly compressed and form a non cubic structure. The splitting of the E" and E' states increases as the oxygen atoms are further distorted from the cubic structure. As more Ga atoms are deposited on to the surface of the films, oxygen atoms surrounding the $\mathrm{Ce}^{3+}$ ion are decompressed and form a cubic structure. As a result, the splitting between the $\mathrm{E}^{\prime \prime}$ and $\mathrm{E}^{\prime}$ states decreases with the Ga content. Consequently, the $\mathrm{Y}_{3}(\mathrm{AlGa})_{5} \mathrm{O}_{12}: \mathrm{Ce}^{3+}$ films have noticeably shorter emission wavelengths (higher energy) compared to $\mathrm{Y}_{3}(\mathrm{AlGa})_{5} \mathrm{O}_{12}: \mathrm{Ce}^{3+}$ powder phosphor indicating that there is more $\mathrm{Ga}$ in the films than in the powder. The shift in the PL wavelengths may therefore be ascribing to the slight change in environment from the powder to the thin films.

The excitation spectra shown in figure 10 were measured from the $510 \mathrm{~nm}$ emission from the films. A slight shift in these peaks to lower wavelengths occurred if compared to the powder, figure 1. The peaks are also much broader than that of the powder with an estimated FWHM value of $33 \mathrm{~nm}$ and $55 \mathrm{~nm}$ respectively.

Depth profiles of several thin films as deposited and after heat treatment at $800^{\circ} \mathrm{C}$ in open atmosphere were performed and are shown in Figure 11. The depth profiles are from the $\mathrm{Y}_{3}(\mathrm{AlGa})_{5} \mathrm{O}_{12}: \mathrm{Ce}^{3+}$ thin films and the $\mathrm{SiO}_{2}$ on top of the Si substrates.

By using the point (depth) where the Y concentration in the AES profiles is about $50 \%$ of the maximum Y concentration as an estimation of the film thickness the thicknesses for the vacuum, $\mathrm{O}_{2}$ and $\mathrm{Ar}$ background prepared layers were determined as $120 \mathrm{~nm}, 230 \mathrm{~nm}$ and $270 \mathrm{~nm}$, respectively. The films prepared in vacuum are clearly much thinner than the rest of the films. This might be due to the fact that the plume (in vacuum) is energetic when arriving on the 
substrate resulting in re-sputtering and reflection of the plume atoms which leads to the thin layer as well as a smooth surface. The effect of the $\mathrm{Ar}$ and $\mathrm{O}_{2}$ atmosphere on the thicknesses is clear. It is therefore clear that the angular distribution, as pointed out above, of the plume atoms is influenced by the mass density of the background gas and therefor the different thicknesses. The heat treatment did not change the distribution of the elements significantly except for the broader interfaces between the YAGG and the $\mathrm{SiO}_{2}$, indicating that some diffusion did take place at the interfaces. The oxygen concentration for the $\mathrm{O}_{2}$ background sample is slightly higher than the other films as expected causing the oxygen loss from the deposition process (light atoms in a background gas are scattered much more than heavy atom) to be filled up again to be closer to the stoichiometry of the target.

Figure12 shows an RBS spectrum of the $\mathrm{O}_{2}, 20$ mtorr film. The red line is the best fit simulated on the RBS data using the Rutherford universal manipulation program (RAMP) program. From the RBS the stoichiometry of the films was comparable to that of the commercial powder (Y:Al:Ga:O - 3: $2: 3: 12$ ). The RBS spectra obtained when the films were irradiated with 2Me ${ }^{4} \mathrm{He}^{+}$ions looked similar for all the films.

\section{Conclusion}

Commercial available YAGG:Ce powder was successfully characterized. Thin films of the YAGG:Ce phosphor powder were successfully prepared in different gas environments using the PLD technique. Various surface analyzing techniques were used to characterize the morphological and luminescent properties. XRD showed a slight improvement in the crystallization of the films after the films were annealed with better crystallization taking place in films deposited in an $\mathrm{O}_{2}$ background. These films also showed the highest PL intensity when 
excited with a xenon lamp. The AES depth profiles indicated the films had different thickness and the distribution of elements on the layer to be homogeneous. PLD proved to be a good technique to grow the films of this phosphor as the RBS data showed that the stoichiometry was maintained from the powder to the film form. The results given in this paper therefore indicates that oxygen at a pressure of 20 mtorr provides good conditions in the chamber to grow films with high PL intensity and good morphological characteristics.

\section{Acknowledgement}

Special thanks to Brian Yalisi and Dr Lorinda Wu at the NLC, CSIR National Laser Centre, Rental Pool Programme, in Pretoria for assisting with the film growth using the PLD technique.

Dr Coetsee-Hugo for obtaining the AES depth profiles. A special thanks to iThemba Labs in Cape Town for RBS measurements. This work is based on the research supported by the South African Research Chairs Initiative of the Department of Science and Technology and National Research Foundation of South Africa. The University of the Free State Cluster program for financial support.

\section{References}

1. M. Fasoli, A. Vedda, M. Nikl, C. Jiang, B.P. Uberuaga, D.A. Andersson, K.J. McClellan, and C.R. Stanek, Phys. Rev. B 84, 081102(R) (2011) 4 pages

2. R. Hansel, S. Allison and G. Walker, J Mater. Sci. 45 (2010) 146-150

3. Jimmy Kuo-Wei Chen, The electrical and optical properties of doped Yttrium, Aluminum Garnets, PhD thesis, University of California, Berkeley (1987) p 77.

4. Fengxia Xin, Shilong Zhao, Shiqing Xu, Guohua Jia, Degang Deng, Huanping Wang, Lihui Huang, Journal of Rare Earths 30(1) (2012) 21-24. 
5. Yanhui Wang, Jianhui Zhang, Dejian Hou, Hongbin Liang, Pieter Dorenbos, Shuaishuai Sun, Ye Tao, Opt. Mat. 34 (2012) 1214-1218.

6. R. Hua, B. Lei, D. Xie and C. Shi, J. Solid State Chem. 175 (2003) 284.

7. T.A. Obrien, P.D. Rack, P.H. Holloway and M.C. Zerner, J. Lumin. 78 (1998) 245

8. E. Coetsee, J.J. Terblans, O.M. Ntwaeaborwa and H.C. Swart, Physica B: Physics of Condensed Matter 404 (22) (2009) 4426 - 4430.

9. L. van Pieterson, M.F. Reid, R. T. Wegh, S. Soverna and A. Meijerink, Phys. Rev. B 65 (2002) 045113.

10. S.W. Allison, G.T. Gillies, A.J. Rondinone and M.R. Cates, Nanotechnology 14 (2003) 859.

11. H. Bechtel, P. Schmidt, W. Busselt and S. Baby, Schreinemacher Philips Research Europe Aachen, D-52066 Aachen, Germany; ABSTRACT A new phosphor technology for phosphor converted light-emitting

12. H.C. Swart, E Coetzee, J.J. Terblans, O.M. Ntwaeaborwa, P.D. Nsimama, F.B. Dejene and J.J. Dolo, 101(4) (2010) 633-638.

13. J. Choe, Mater. Res. Innov. 6(5-6) (2002) 238-241.

14. J.S. Bae, K.S. Shim, S.B. Kim,J.H. Jeong, S.S. Yi and J.C. Park, J. Cryst. Growth 264 (2004) 290

15. J. Schou, Appl. Surf. Sci. 255 (2009) 5191-5198

16. HASYLAB, Beamline I: SUPERLUMI, http:/hasylab.desy.de/facilities/doris_iii/ beamlines/i_superlumi (accessed on Jan. 2012)

17. Jennifer L. Wu, Gautam Gundiah, A.K. Cheetham, Chem. Phys. Let. 441 (2007) 250254. 
18. Wen-Hsuan Chaoa, Ren-Jye Wub, Tai-Bor Wua, J. of Alloys and Comp. 506 (2010) 98102.

19. M. Kottaisamy, P. Thiyagarajan, J. Mishra, M.S. Ramachandra Rao, Mat. Res. Bull. 43 (2008) 1657-1663

20. T. Tomiki, H. Akamine, M. Gushiken, Y. Kinjoh, M. Miyazato, T. Miyazato, N. Toyokawa, M. Hiraoka, N. Hirata, Y. Ganaha, and T. Futemma, J. Phys. Soc. Jpn. 60(7), (1991) 2437-2445.

21. http://www.phosphoo-technology.com/products/ctr.htm [Accessed 29 May 2012]

22. S. Amoruso, R. Bruzzese, N. Spinelli, R. Velotta, M. Vitiello and X. Wang, Phys. Rev. B 67 (2003) 224503.

23. S. Amoruso, B. Toftmann and J.Schou, Phys. Rev. E 69 (2004) 056403.

24. H.C. Lee, D.E. Zeitoun, J.D. Parisse, M. Sentis and W. Marine, Phys. Rev. E 62 (2000) 4152.

25. Y. Nakata, W.K.A. Kumuduni, T. Okada, M. Maeda, Appl. Phys. Lett. 64 (1994) 2599.

26. J.M. Warrender, M.J. Aziz, Phys. Rev. B 75 (2007) 085433.

27. R.F. Wood, K.R. Chen, J.N. Leboeuf, A.A. Puretzky and D.B. Geohegan, Phys. Rev. Lett. 79 (1997) 1571.

28. Y. Wang, J. Zhang, D. Hou, H. Liang, P. Dorenbos, S. Sun and Y. Tao, Opt. Mat. 34 (2012) 1214-1218.

29. Hansel R, Allison S and Walker G 2010 J Mater Sci 45 146-150 


\section{Figure captions}

Figure 1: PL excitation and emission spectra of $\mathrm{Y}_{3}(\mathrm{AlGa})_{5} \mathrm{O}_{12}: \mathrm{Ce}^{3+} . \mathrm{E}_{\mathrm{ex}}=439 \mathrm{~nm}$ and $\mathrm{E}_{\mathrm{em}}=512$ nm.

Figure 2: The emission and excitation spectra of the $\mathrm{Y}_{3}(\mathrm{AlGa})_{5} \mathrm{O}_{12}: \mathrm{Ce}^{3+}$ phosphor measured with an excitation wavelengths of 178 and $225 \mathrm{~nm}$ and at an emission wavelength of $512 \mathrm{~nm}$.

Figure 3 The energy diagram of the $\mathrm{Y}_{3}(\mathrm{AlGa})_{5} \mathrm{O}_{12}: \mathrm{Ce}^{3+}$ phosphor showing the excitation and emission as compiled from the emission and excitation spectra.

Figure 4: XRD spectra of YAGG:Ce powder and films deposited at $300{ }^{\circ} \mathrm{C}$ in different gas atmospheres.

Figure 5: XRD spectrum of YAGG:Ce powder and films after annealing at $800{ }^{\circ} \mathrm{C}$ in open air.

Figure 6: AFM micrographs of the film deposited in (a) vacuum (1.6 x $10^{-6}$ mbar), (b) 20 mtorr Argon and (c) 20 mtorr $\mathrm{O}_{2}$ at a substrate temperature of $300{ }^{\circ} \mathrm{C}$

Figure 7: SEM micrograph of the films deposited in (a) vacuum (1.6 x $\left.10^{-6} \mathrm{mbar}\right)$ and (b) 20 mtorr Argon and (c) 20 mtorr $\mathrm{O}_{2}$ at a substrate temperature of $300{ }^{\circ} \mathrm{C}$

Figure 8: PL intensity of the films deposited in $\mathrm{O}_{2}$ at various background gas pressures in the chamber, with the inset the relative maximum PL intensity of films deposited in $\mathrm{O}_{2}$ and in $\mathrm{Ar}$ at different pressures as indicated.

Figure 9. Energy level diagram for YAG: Ce and YAGG:Ce (not drawn to scale) [26]

Figure 10: A typical excitation spectrum of the films measured for an emission of $510 \mathrm{~nm}$.

Figure 11: Depth profiles of films before and after annealing. 
Figure 12: RBS spectrum of a film deposited in $\mathrm{O}_{2}, 20$ mtorr at $300^{\circ} \mathrm{C}$ substrate temperature showing the best fit (red). 


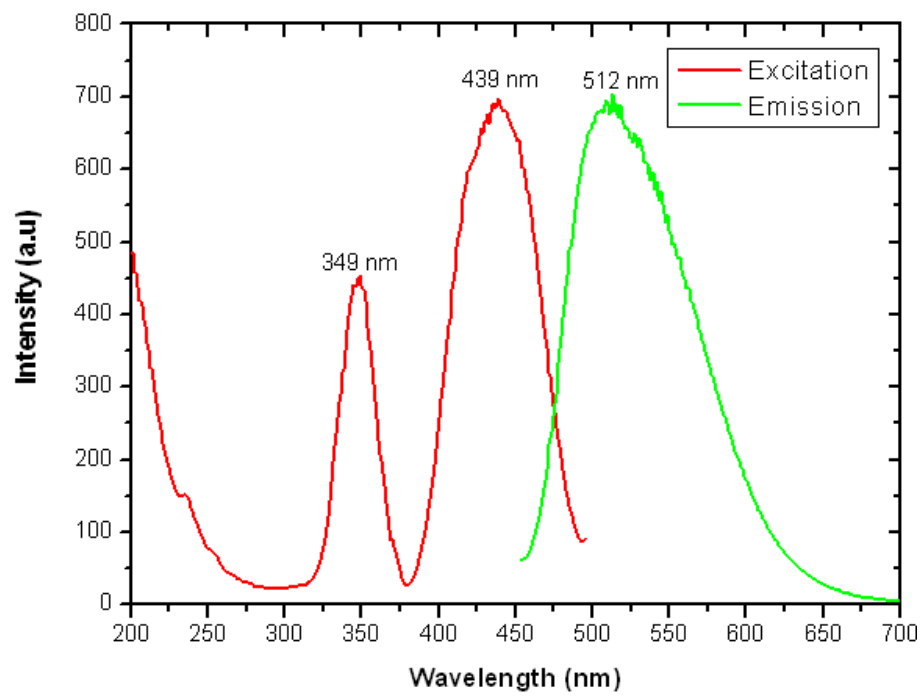

Figure 1: $P L$ excitation and emission spectra of $\mathrm{Y}_{3}(\mathrm{AlGa})_{5} \mathrm{O}_{12}: \mathrm{Ce}^{3+} . \mathrm{E}_{\mathrm{ex}}=439 \mathrm{~nm}$ and $E_{e m}=512 \mathrm{~nm}$. 

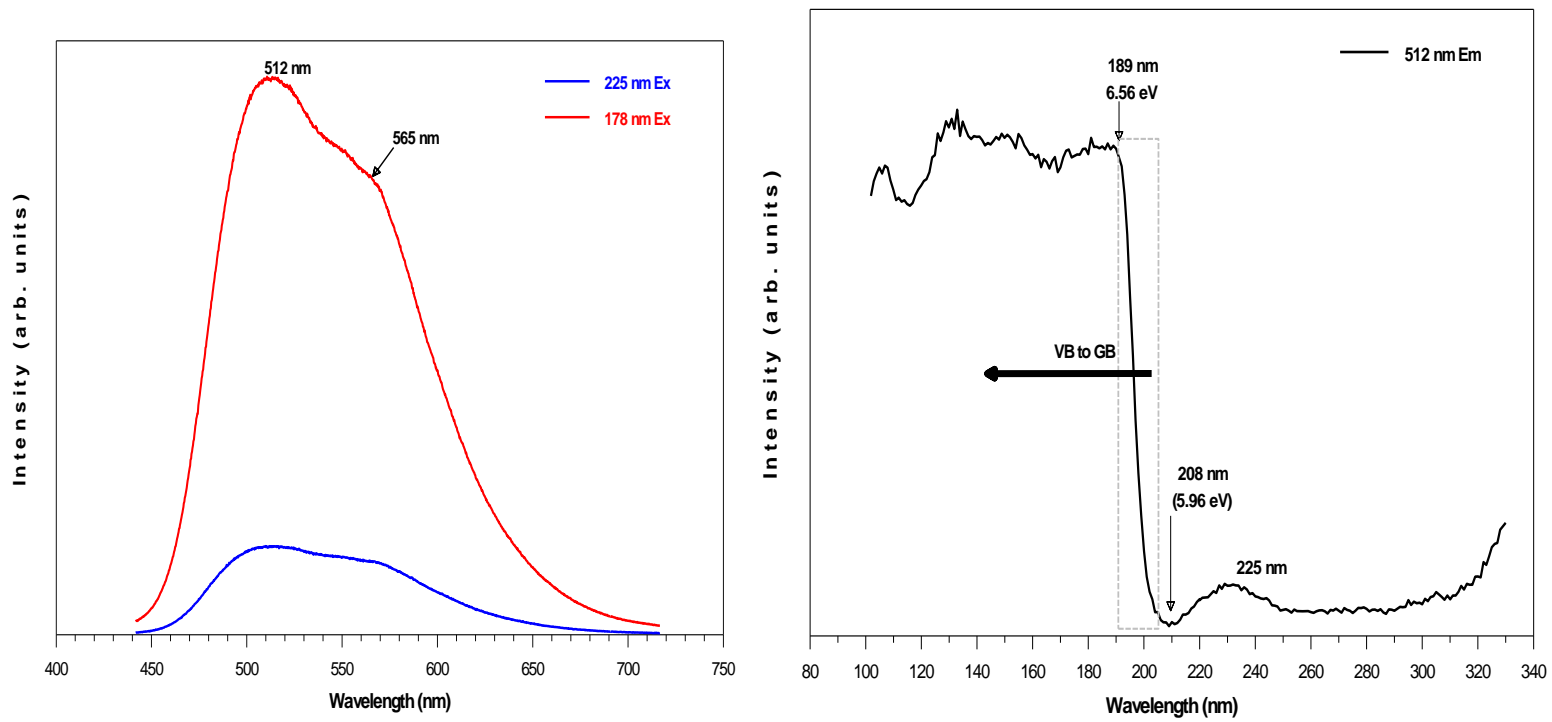

Figure 2: The emission and excitation spectra of the $\mathrm{Y}_{3}(\mathrm{AlGa})_{5} \mathrm{O}_{12}: \mathrm{Ce}^{3+}$ phosphor measured with an excitation wavelengths of 178 and $225 \mathrm{~nm}$ and at an emission wavelength of $512 \mathrm{~nm}$. 


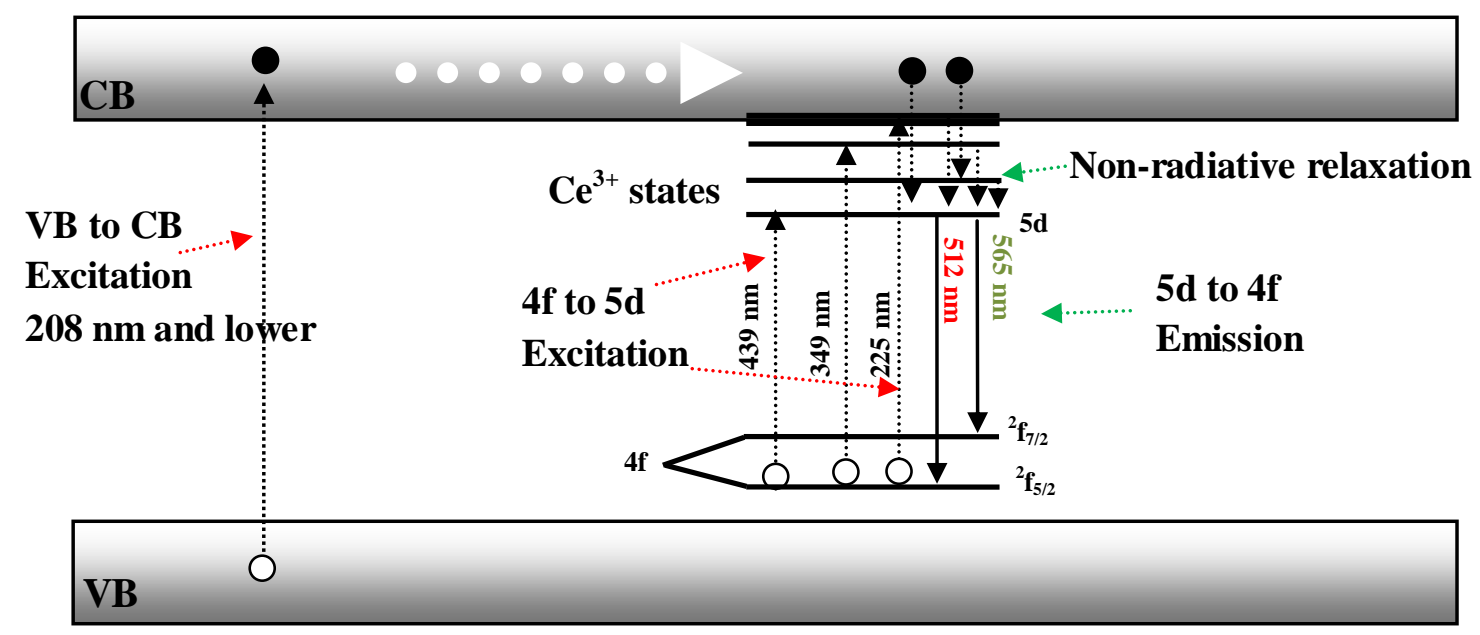

Figure 3 The energy diagram of the $\mathrm{Y}_{3}(\mathrm{AIGa})_{5} \mathrm{O}_{12}: \mathrm{Ce}^{3+}$ phosphor showing the excitation and emission as compiled from the emission and excitation spectra. 


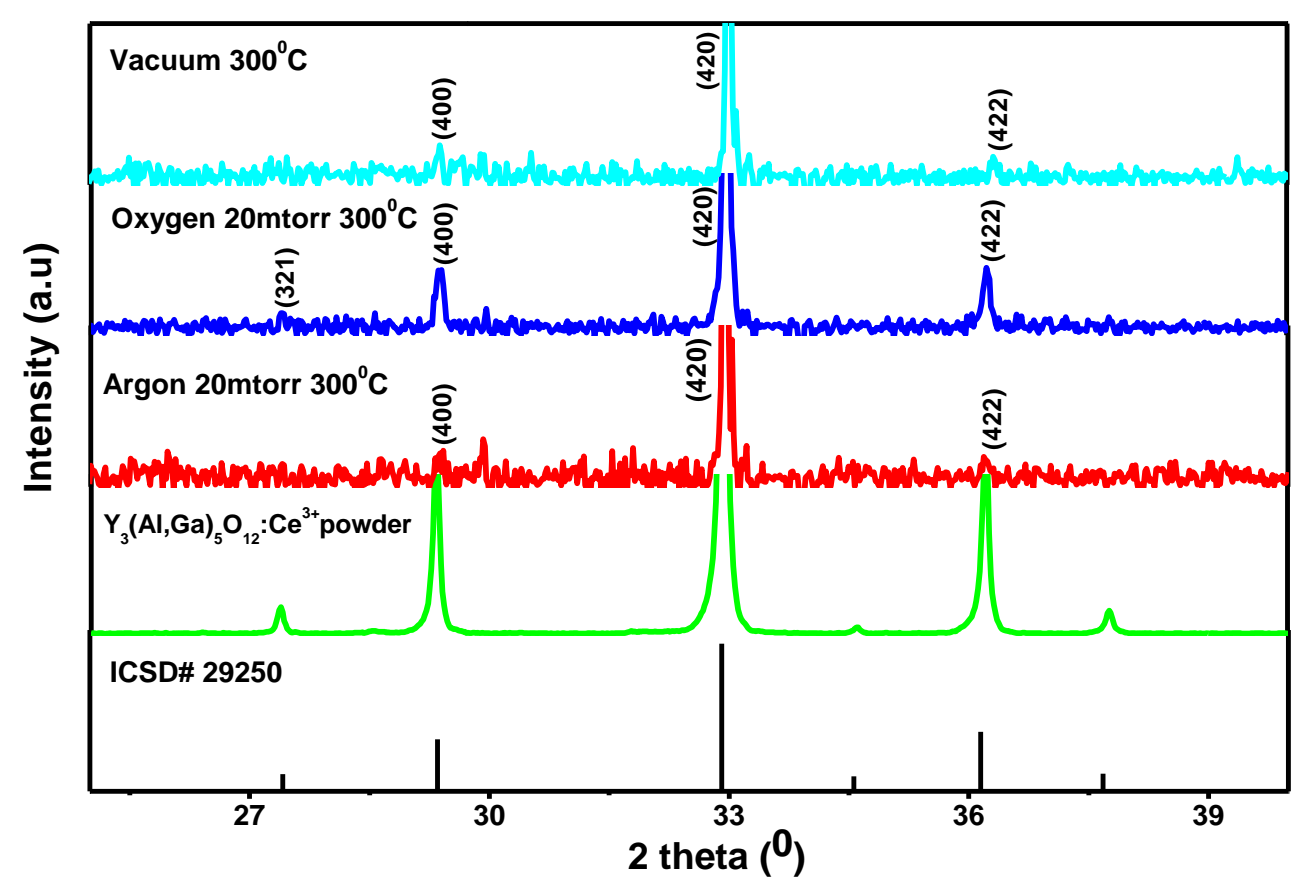

Figure 4: XRD spectra of YAGG:Ce powder and films deposited at $300{ }^{\circ} \mathrm{C}$ in different gas atmospheres. 


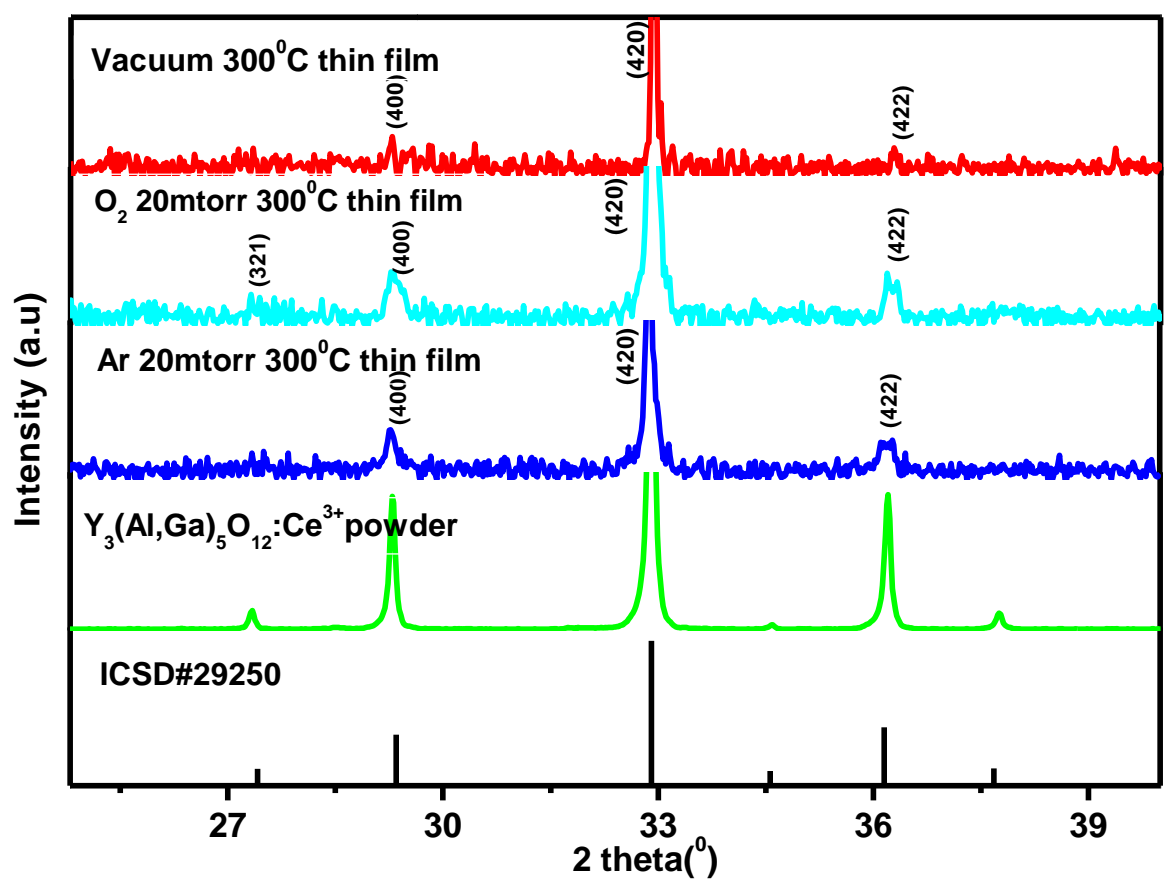

Figure 5: XRD spectrum of YAGG:Ce powder and films after annealing at $800{ }^{\circ} \mathrm{C}$ in open air. 


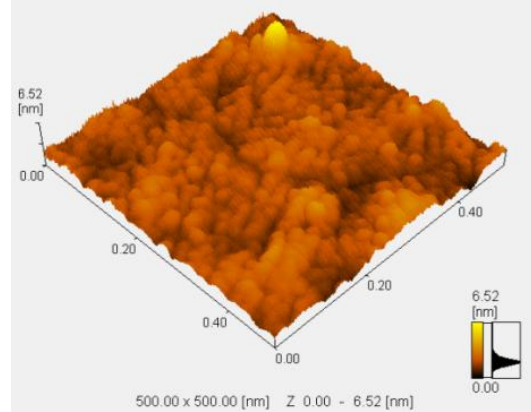

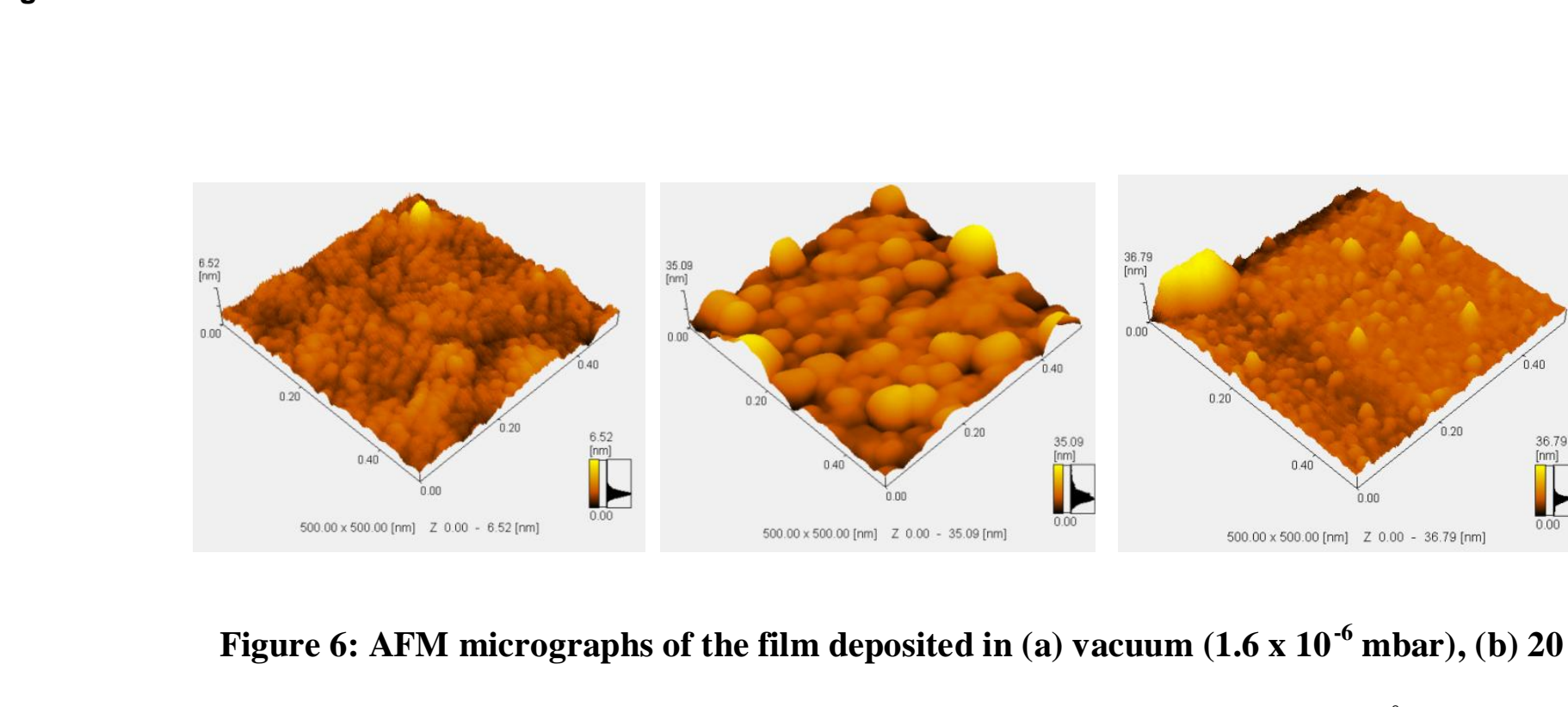

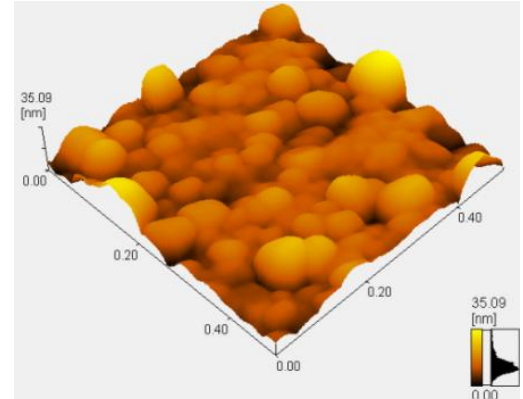

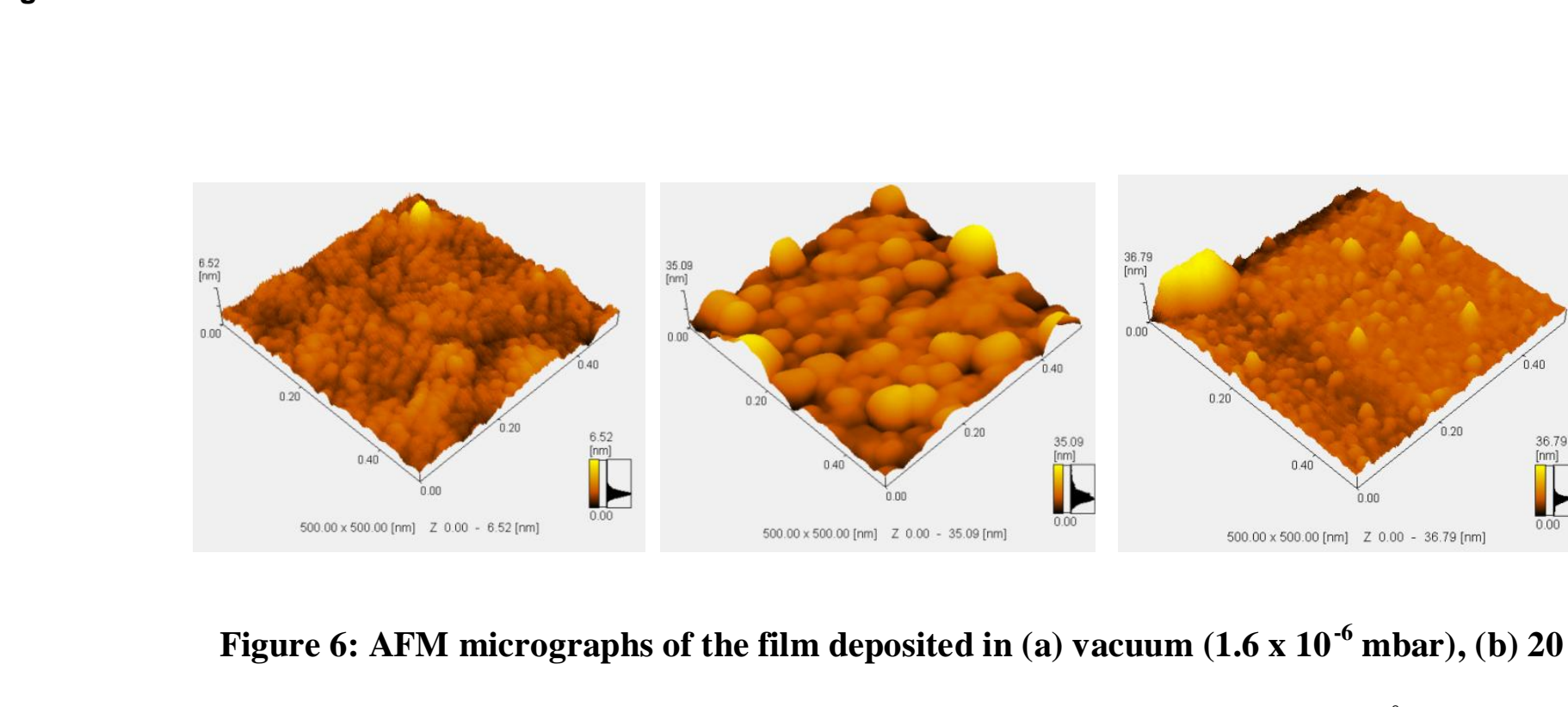

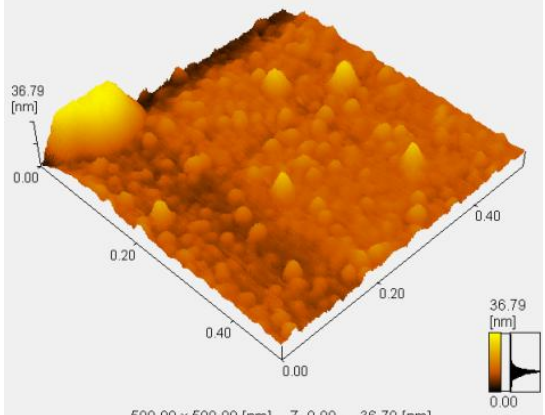

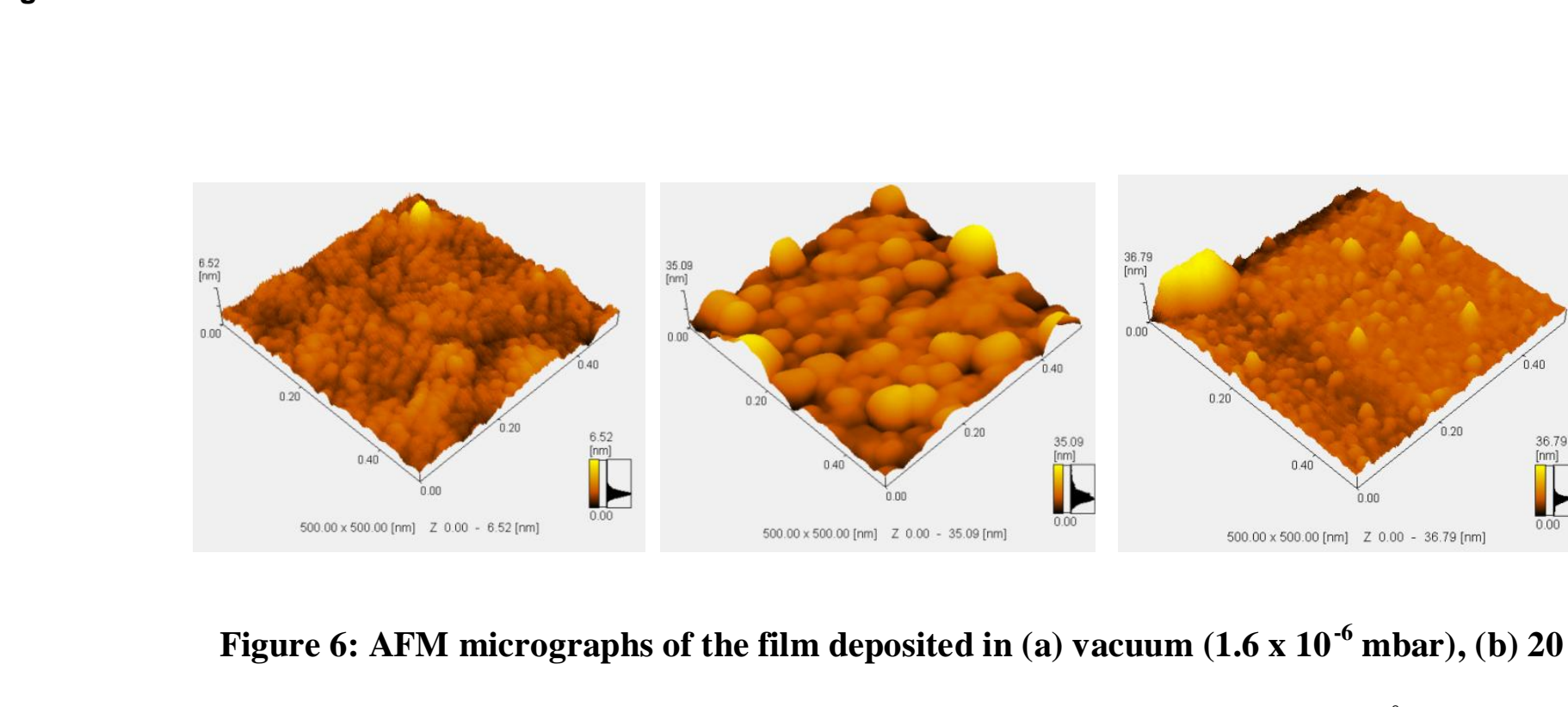

Figure 6: AFM micrographs of the film deposited in (a) vacuum (1.6 $\left.\mathbf{x} \mathbf{1 0}^{-\mathbf{6}} \mathbf{m b a r}\right)$, (b) 20 mtorr Argon and (c) 20 mtorr $\mathrm{O}_{2}$ at a substrate temperature of $300{ }^{\circ} \mathrm{C}$ mtorr Argon and (c) 20 mtorr $\mathrm{O}_{2}$ at a substrate temperature of $300{ }^{\circ} \mathrm{C}$

\author{
(1)
} 0

(1)



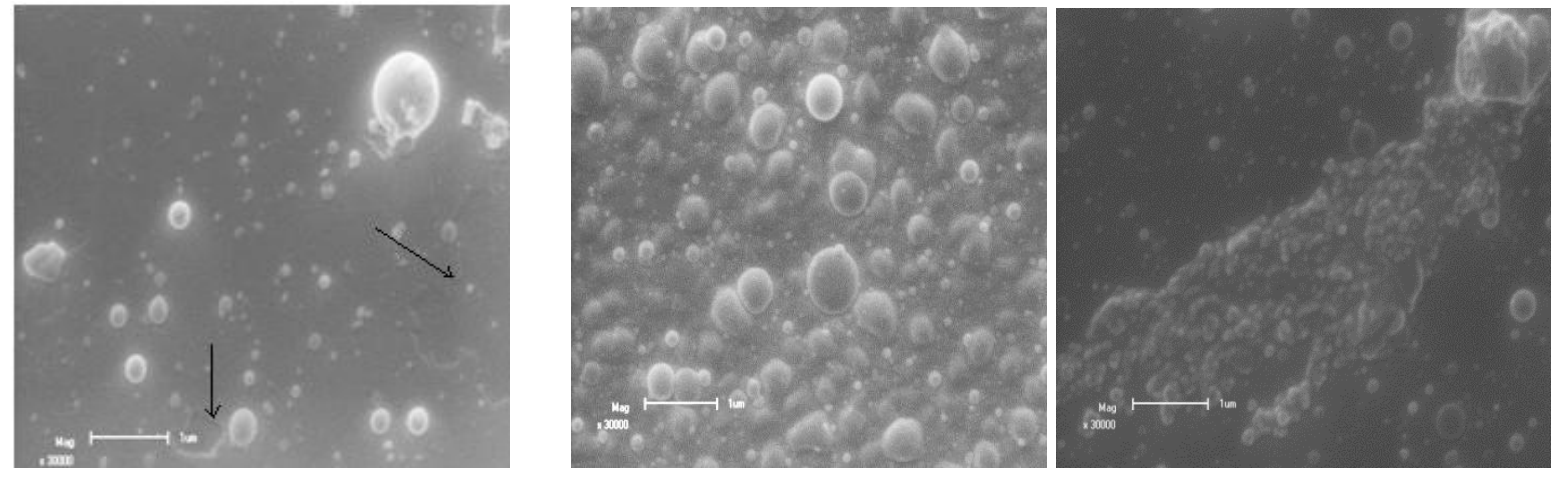

Figure 7: SEM micrograph of the films deposited in (a) vacuum (1.6 x $\left.10^{-6} \mathrm{mbar}\right)$ and (b) 20 mtorr Argon and (c) 20 mtorr $\mathrm{O}_{2}$ at a substrate temperature of $300{ }^{\circ} \mathrm{C}$

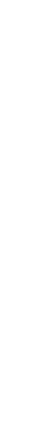
. 


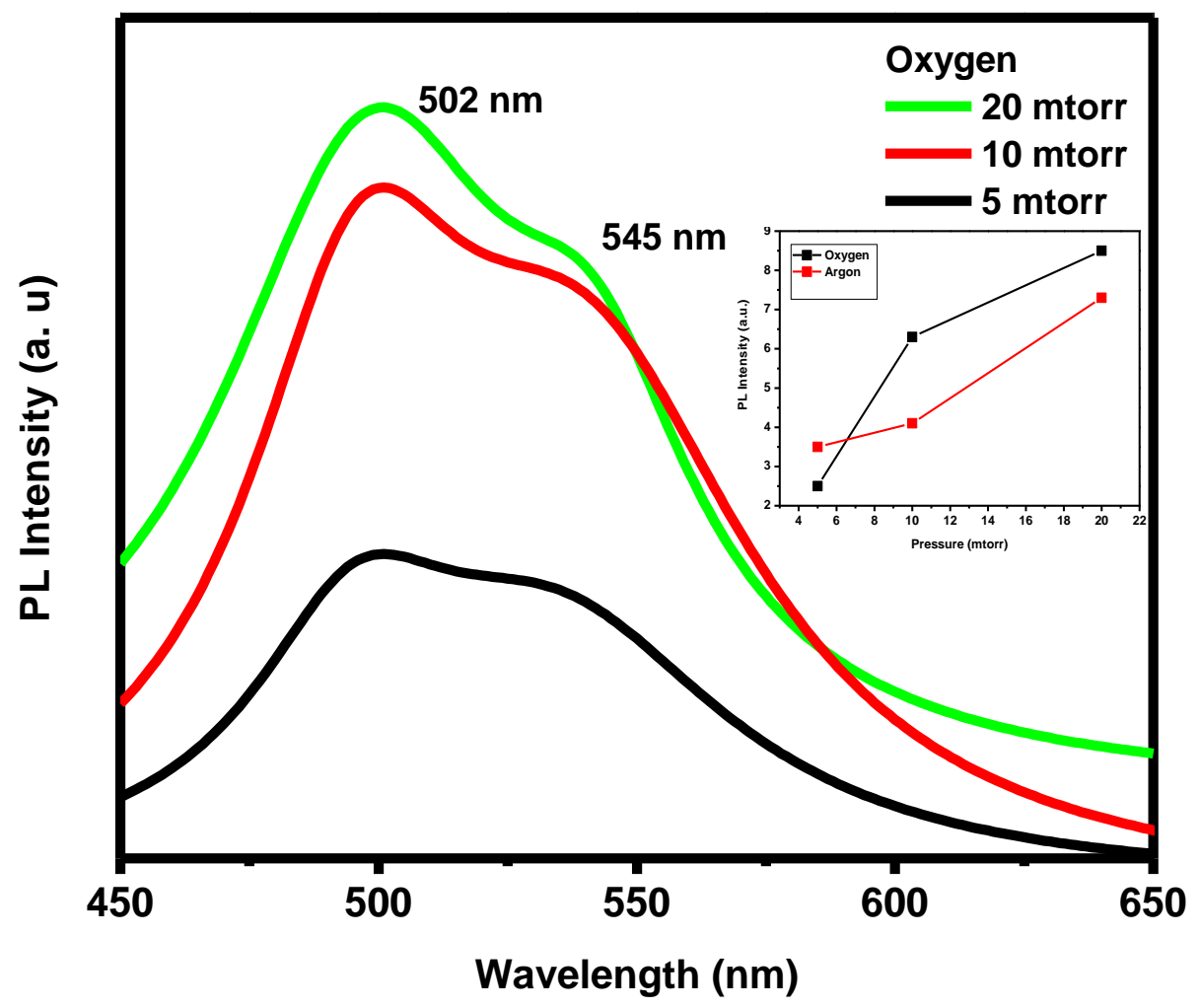

Figure 8: PL intensity of the films deposited in $\mathrm{O}_{2}$ at various background gas pressures in the chamber, with the inset the relative maximum PL intensity of films deposited in $\mathrm{O}_{2}$ and in Ar at different pressures as indicated. 
Figure 9. Energy level diagram for YAG: Ce and YAGG:Ce (not drawn to scale) [26]

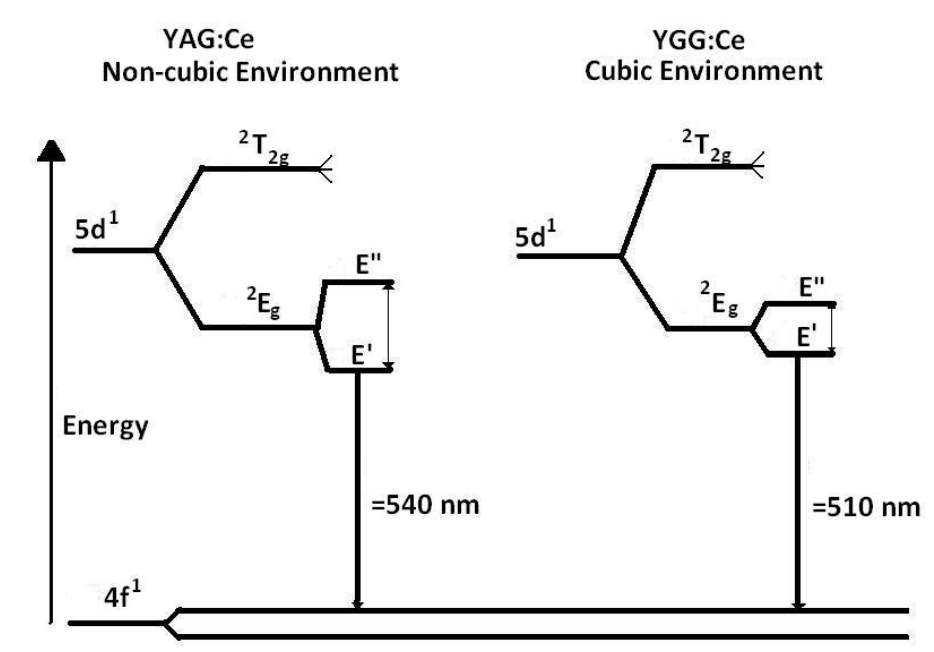

YAG:Ce

rawn to scale) [26]

(1)

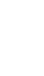

Figure 9. Energy level diagram for YAG: Ce and YAGG:Ce (not drawn to scale) (26) (1)

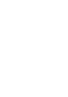




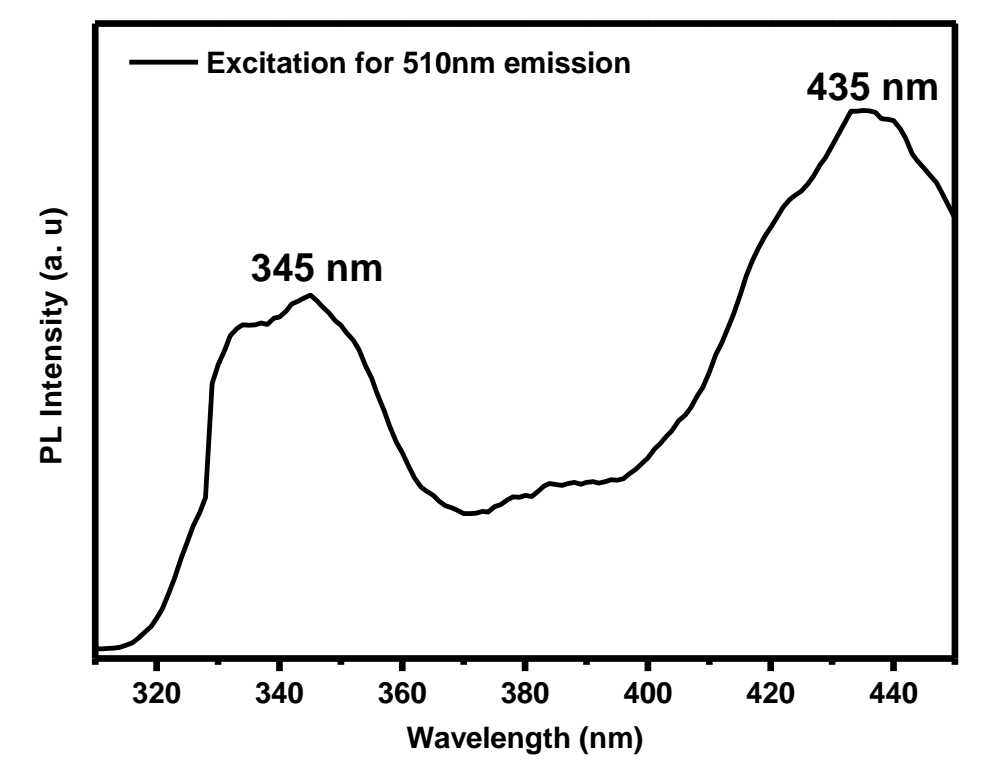

Figure 10: A typical excitation spectrum of the films measured for an emission of $510 \mathbf{~ n m . ~}$

Figure 10: A typical excitation spectrum of the films measured for an emission of 510 nm. 

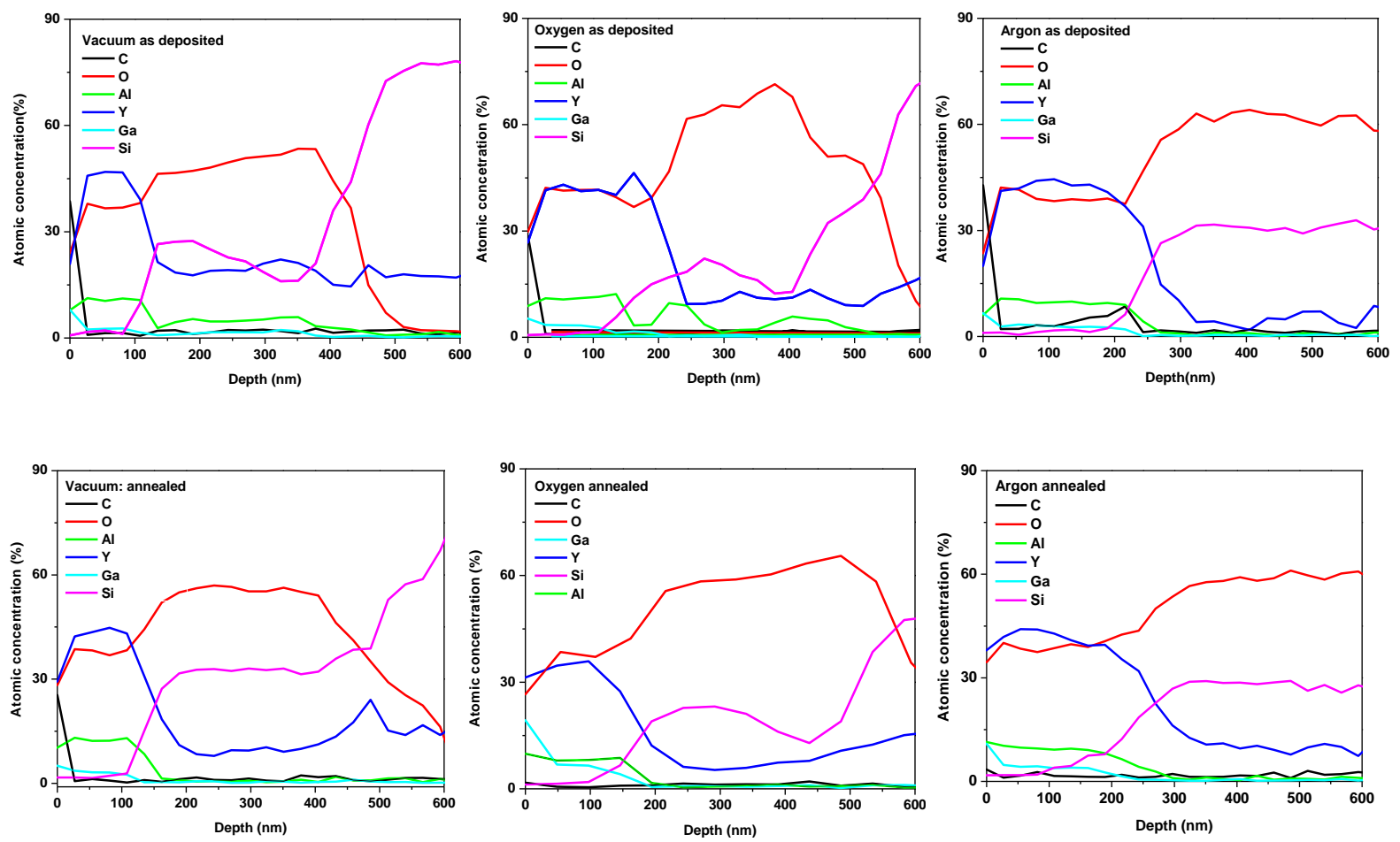

Figure 11: Depth profiles of films before and after annealing. 


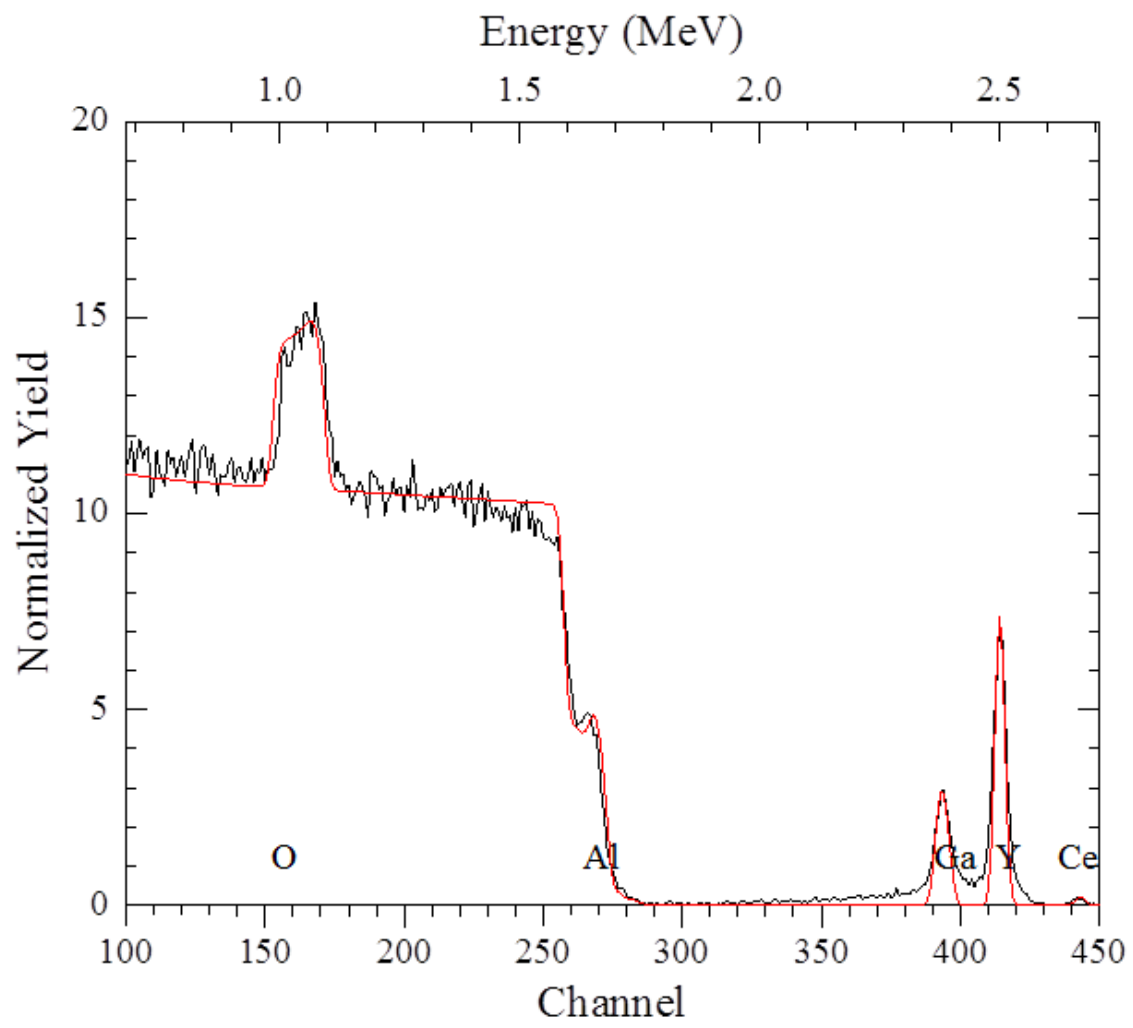

Figure 12: RBS spectrum of a film deposited in $\mathrm{O}_{2}, 20$ mtorr at $300^{\circ} \mathrm{C}$ substrate temperature showing the best fit (red). 